\title{
MADUREIRA, CAPITAL DOS SUBÚRBIOS (1940-1960): CARNAVAL E COMÉRCIO NA PRODUÇÃO DE UMA COMUNIDADE IMAGINADA
}

\author{
Annelise Caetano Fraga ${ }^{1}$ \\ Miriam de Oliveira Santos ${ }^{2}$

\section{Introdução}

Nos últimos anos do século XIX, o Rio de Janeiro começou a se tornar um polo da colônia portuguesa: a cidade recebeu um fluxo contínuo de imigrantes lusitanos, especialmente após 1890 (Chalhoub, 1986: 5). Os estudos disponíveis sobre a imigração portuguesa para o Brasil (Bassanezi, 1995; Costa Leite, 2000; Menezes, 2000; Neves, Ferreira, 2002; Levy, 1974; Rowland, 1992) apontam que ela é significativa ao longo de todo o século XX, apesar de a imigração em geral ter diminuído bastante em função da Lei de cotas para imigrantes, promulgada por Getúlio Vargas na década de 1930. Estes imigrantes provinham, em sua maior parte, das regiões rurais de Portugal, especialmente dos Açores, da Ilha da Madeira e das províncias do Norte (Minho, Beira e Trás-osMontes). Também é consensual que, especialmente no século XX, esta é uma imigração majoritariamente masculina, com baixa taxa de retorno e voltada predominantemente para áreas urbanas.

TABELA 1: Imigração portuguesa para o Brasil (1500-1991)

\begin{tabular}{|c|c|}
\hline Décadas & Número de imigrantes \\
\hline $1500-1700$ & 100.000 \\
\hline $1701-1760$ & 600.000 \\
\hline $1808-1817$ & 24.000 \\
\hline $1827-1829$ & 2.004 \\
\hline $1837-1841$ & 629 \\
\hline $1856-1857$ & 16.108 \\
\hline $1881-1900$ & 316.204 \\
\hline $1901-1930$ & 754.147 \\
\hline $1951-1950$ & 148.699 \\
\hline $1961-1960$ & 235.635 \\
\hline $1981-1991$ & 54.767 \\
\hline
\end{tabular}

Fonte: Instituto Brasileiro de Geografia e Estatística (IBGE).

\footnotetext{
${ }^{1}$ Universidade Federal Rural do Rio de Janeiro, Brasil.

${ }^{2}$ Universidade Federal Rural do Rio de Janeiro, Brasil.
} 
Trabalhando com os dados desagregados do censo é possível comprovar essa percepção:

Tabela 2: Imigrantes portugueses* por sexo

\begin{tabular}{|l|c|c|c|c|c|c|}
\hline Ano & Homens & $\begin{array}{c}\text { \% em relação } \\
\text { ao total de } \\
\text { homens } \\
\text { estrangeiros }\end{array}$ & Mulheres & $\begin{array}{c}\text { \% em relação } \\
\text { ao total de } \\
\text { mulheres } \\
\text { estrangeiras }\end{array}$ & $\begin{array}{c}\text { Total de } \\
\text { homens } \\
\text { estrangeiros }\end{array}$ & $\begin{array}{c}\text { Total de } \\
\text { mulheres } \\
\text { estrangeiras }\end{array}$ \\
\hline 1920 & 291.198 & $31,6 \%$ & 142.379 & $22,1 \%$ & 922.958 & 643.003 \\
\hline 1940 & 221.195 & $27,9 \%$ & 136.979 & $22,3 \%$ & 793.276 & 613.292 \\
\hline 1950 & 206.304 & $30,3 \%$ & 130.552 & $24,4 \%$ & 679.962 & 534.222 \\
\hline 1960 & 247.119 & $36,1 \%$ & 183.928 & $32,4 \%$ & 683.919 & 568.548 \\
\hline 1970 & 247.197 & $36,8 \%$ & 190.786 & $34,2 \%$ & 671.375 & 557.753 \\
\hline 1980 & 216.724 & $36,1 \%$ & 175.937 & $34,4 \%$ & 599.986 & 510.924 \\
\hline 1991 & 140.320 & $30,3 \%$ & 123.290 & $34,4 \%$ & 463.159 & 358.631 \\
\hline
\end{tabular}

Como a maioria dos imigrantes portugueses vinha de zonas rurais e apresentava baixa escolaridade, cria-se no Rio de Janeiro o estereótipo do português grosso, burro e malvestido.

\section{O bairro de Madureira e o estigma do subúrbio}

Situado na zona norte do Rio de Janeiro, é um bairro de classe média e média baixa. Seu nome faz referência ao boiadeiro e arrendatário da fazenda Campinho, Lourenço Madureira. O desmembramento gradativo desta fazenda, ao longo do século XIX, deu origem ao bairro de Madureira. O mesmo processo se repetiu na maior parte dos bairros do subúrbio.

Em 1858, foi inaugurada a linha férrea Central do Brasil, e a estação de Madureira data de 1890. Tais fatos trouxeram maior dinamismo e estimulo à ocupação desta localidade. Segundo Abreu (1984), até o fim do século XIX, o serviço dos trens 
suburbanos era restritivo, com horários irregulares e passagem cara. ${ }^{3}$ Habitava os subúrbios, então, uma população com remuneração estável e que não dependia da busca diária pelo trabalho. Era formada em sua maioria por funcionários civis e militares de baixo escalão, comerciantes e alguns operários (Abreu, 1984).

O subúrbio carioca aos poucos passou a ser reconhecido como a zona da cidade "onde o trem passa" ${ }^{4}$ A abertura gradual de novas estações ao longo dos bairros e o barateamento do custo da passagem estimulou um movimento crescente de ocupação dos subúrbios, sobretudo por classes populares expulsas pelo processo de remodelação da cidade. Embora este processo já estivesse em andamento desde o fim do século XIX, é durante a Reforma Passos ${ }^{5}$ (1902-1906) que se torna mais marcante. Popularmente conhecida como "bota-abaixo", desalojou milhares de pessoas, habitantes de cortiços, que foram obrigadas a buscar moradia em lugares distantes do centro da cidade.

A partir desta intervenção urbana, o subúrbio foi progressivamente identificado como local destinado à moradia das camadas populares. Se, por um lado, a Reforma Passos foi um golpe aos anseios elitistas das camadas médias ${ }^{6}$ suburbanas, por outro, fortaleceu entre estes setores o desejo de se distinguir desta população marginalizada, que vivia de forma indefinida entre o mundo legal e ilegal e que tanto contribuía para a degradação de suas zonas (O Subúrbio, n. 181, 21/01/1911 apud Abreu; 1984).

A imprensa de bairro suburbana ${ }^{7}$ fornece um precioso registro das transformações populacionais e urbanas pelas quais passa esta região. Ela é utilizada como instrumento

\footnotetext{
3 "Para muitos trabalhadores, a moradia nas regiões centrais da cidade era condição indispensável para a sobrevivência, já que o ganha-pão tinha que ser procurado diariamente nas ruas da cidade. Precisavam, portanto, da aglomeração para conseguir trabalho e não podiam arcar com gastos de transporte e aluguéis muito caros" (Abreu, 1984).

${ }^{4}$ Corresponde aos bairros da zona norte servidos pela Estrada de Ferro Central do Brasil e Leopoldina.

${ }^{5}$ Remodelação urbana do centro do Rio de Janeiro que visava ajustar a cidade, com características tipicamente coloniais, às novas necessidades do sistema capitalista. Ao expulsar a população pobre que habitava o centro para outras áreas da cidade, a reforma simultaneamente resolveu a questão do controle social, a questão sanitária e adequou a cidade aos padrões estéticos europeus.

${ }^{6}$ A produção sobre camadas médias urbanas no Rio de Janeiro (Velho, 1994; Heilborn, 1984; Salem, 1985) privilegia o estudo de critérios relacionados ao status, estilo de vida e ethos e procura analisar como este estrato social se autorrepresenta e percebe a sua posição social; quais são os signos e estratégias utilizadas para se definir e distinguir na estrutura social.

${ }^{7}$ Gazeta Suburbana (Todos os Santos - 10/1883 a 10/1885); Gazeta Suburbana (Méier - 08/09/1910 a 31/12/1912 ...05/04/119 a 27/08/1921); O Suburbano (01/03/1900 a 01/12/1900); O Subúrbio (Méier 13/05/1903 a05/04/1904...27/07/1907 a 02/09/1911); Echo Suburbano (Engenho de Dentro - 03/08/1901 a 26/10/1901); Echo Suburbano (Madureira - 24/04/1911 a 31/12/1911); Progresso Suburbano (02/03/1902); Subúrbios em Revista (1948-1957), consultados na Biblioteca Nacional.
} 
de denúncia das precárias condições de infraestrutura urbana e para reivindicação por melhorias ao Estado:

Melhoramentos pelos subúrbios, melhoramentos para a zona suburbana. Será este o nosso constante grito (...) Somos suburbanos, defensores dos subúrbios e para trabalharmos em benefício dessas paragens nunca sentiremos extenuações (Echo Suburbano - Madureira - II:173, 08/07/1911).

Mas, sobretudo, esta imprensa dedica-se a mostrar a distinção dos subúrbios e de sua gente, revertendo imagens estigmatizantes da região vinculadas à pobreza e à marginalidade. Nas notas publicadas na imprensa de bairro desde longa data, destacamse os valores elitistas das camadas médias suburbanas, enfatizando a ocupação "aristocrática" e a riqueza da vida social dos subúrbios, assim como o bucolismo e a salubridade, tanto higiênica quanto moral, de suas zonas em relação ao adensamento populacional e as precárias condições sanitárias das moradias do centro da cidade.

Da estação de São Francisco Xavier até Cascadura margeando a estrada de ferro, não há nesse cordão de edificações uma solução de continuidade, os mais lindos chalés, os mais vistosos palacetes e as mais confortáveis vivendas ostentam, com sua materialidade bruta, a força da iniciativa particular (Gazeta Suburbana - Todos os Santos - II: 16, 28/06/1884, apud Abreu, 1984).

Já nas primeiras décadas do século XX, Madureira destaca-se pelo seu crescimento e dinamismo econômico. A criação do Mercado de Madureira (um entreposto de hortifrutigranjeiros) em 1914 é apontada como iniciativa pioneira em torno da qual outras lojas e serviços se desenvolveram. Aos poucos, é consolidada sua imagem como "capital dos subúrbios". Não apenas o comércio é utilizado como um índice de desenvolvimento, mas também a construção de casas e edifícios “imponentes” é apontada como importante iniciativa para o progresso da região suburbana.

Madureira, a humilde estação da central, inaugurada em 1890, alcançou em trinta e dois anos um avanço formidável. Desde 1918 que se transformou o aprazível subúrbio (...) conta com animadíssimos cafés, confeitarias, lojas de moda, armarinhos, mercado, ostentando algum luxo em quatro ou cinco lojas principais (Abreu, 1988:81).

Não é só o impressionante estilo arquitetônico do majestoso solar dos Fonseca, à Rua Carolina Machado, 524, em Madureira que encanta e seduz o visitante. (...) tudo se reveste do mesmo tom de elegância e bom gosto que se harmoniza admiravelmente com o clima que o cerca (Subúrbios em Revista, out. 1949:4). 
Deste modo, consolidam-se aos poucos a centralidade e a influência de Madureira sobre os outros bairros do subúrbio. Se, por um lado, a projeção econômica e social de Madureira reforçava a imagem do progresso e do desenvolvimento do subúrbio como um todo, de outro, o sucesso de Madureira entre os bairros desta região determinava certa hierarquia ou atribuição de status, como o título "capital dos subúrbios" pode sugerir. Assim, considerando o fato de que os bairros eram os locais específicos em que a ação em prol dos subúrbios era realizada e que os mesmos eram também importantes demarcadores na configuração de redes de relações sociais, é pertinente caracterizar de que forma esta ação empreendedora distinguia e hierarquizava grupos e localidades.

Assim, ao descrever a construção de uma verdadeira comunidade imaginada (Anderson, 2008) em Madureira, a partir de critérios de pertencimento, lealdade e identidade com o bairro, entendemos que este movimento estava articulado a um projeto mais amplo de dignificação dos subúrbios e reversão de sua identidade estigmatizada. Contudo, as representações sobre o suburbano típico, que ganham força entre as décadas de 1940 e 1960, têm feições fortemente vinculadas aos valores e anseios dos comerciantes de Madureira que aqui procuramos retratar.

Apesar de o Estado pouco ter feito em benefício das regiões suburbanas ao longo de todos esses anos, o final dos anos 1940, prolongando-se pela década de 1960, caracterizou-se por uma conjunção de processos históricos que permitiram o fortalecimento dos sentimentos e práticas localistas citados anteriormente. Segundo Abreu (1988), os anos 1940/1950 caracterizaram-se pela posição de destaque da burguesia industrial, também pela penetração maciça do capital estrangeiro, marcando o início da febre desenvolvimentista no país. No plano urbano, foi um momento em que a população cresceu de forma espetacular, e o processo de estratificação geográfica se desenvolveu de forma mais ou menos mascarada, em função da proliferação de favelas ${ }^{8}$ por toda a cidade.

A composição social dos subúrbios (ocupado majoritariamente por setores populares) não se modificou. Porém, como os setores populares espalharam-se por toda cidade pela disseminação de favelas, minimizou-se, por certo tempo, o contraste social entre subúrbios, centro e zona sul (Abreu, 1988). Esse quadro, aliado a um período de grande prosperidade comercial e industrial de algumas regiões suburbanas, intensificou

\footnotetext{
${ }^{8}$ Definição adotada por Abreu (1988).
} 
nessas duas décadas a crença das camadas médias de que, finalmente, a hora e a vez dos subúrbios haviam chegado (Fernandez, 1996).

\section{Madureira como "Comunidade Imaginada"}

Nas primeiras décadas do século XX, alguns bairros do Rio de Janeiro destacam-se e aparecem com características peculiares, assim, temos a construção de Copacabana como um bairro "moderno" e de "liberdade" a Tijuca como um bairro "de tradição", com bons colégios e uma sólida classe média, e Madureira como um bairro de comércio popular.

$\mathrm{Na}$ construção desta comunidade imaginada, o mito de origem da vocação comercial do bairro é o surgimento do Mercado de Madureira, apresentado como resultado da "iniciativa particular" de abnegados suburbanos, em sua maioria, lavradores portugueses (Murta et al., 2008). Encontramos em Martins (2009:42), uma referência para a forte presença portuguesa nesta localidade e sua participação no desenvolvimento de um mercado de produtos agrícolas. Segundo o autor, a partir de 1908, a Light ${ }^{10}$ constrói um extenso corredor de transmissão elétrica entre a hidrelétrica de Fontes (município de Nova Iguaçu) e Cascadura (bairro vizinho à Madureira) e concede, em regime de comodato, nas terras paralelas à Linha Auxiliar, entre Costa Barros, Magno e Cascadura, lotes de terra a lavradores portugueses, oriundos em grande parte das ilhas Madeira e Açores. Impedidos de plantar árvores, os imigrantes cultivam cerca de cinco quilômetros de hortas de verduras, legumes e ervas. O comércio de hortaliças estimulou também a comercialização de frutas e outros produtos alimentares que vinham de outras regiões da cidade, fazendo com que Madureira se tornasse um grande centro distribuidor de hortifrutigranjeiros.

Embora a história do mercado registre a participação e o investimento da prefeitura na concessão do espaço e realização de obras de infraestrutura em diversos momentos e endereços nos quais o mercado esteve estabelecido (Martins, 2009), a ênfase na descrição do passado mítico do Mercado de Madureira e da força econômica do comércio do bairro recai sobre o papel da iniciativa particular à revelia do poder público.

\footnotetext{
${ }^{9}$ Ver Velho (1989).

${ }^{10}$ Companhia distribuidora de energia elétrica.
} 
O destaque para a autonomia do Mercado de Madureira em relação ao Estado faz parte do discurso recorrente entre as camadas médias suburbanas de que a prosperidade do bairro é fruto do empenho do setor comercial. Revertia-se, assim a inferioridade e subalternidade dos subúrbios em relação à zona central ${ }^{11}$ e sul da cidade e projetava $o$ segmento social como grupo de prestígio no subúrbio.

Uma das principais estratégias de afirmação deste grupo consistia em converter ou apresentar tudo aquilo que era de interesse privado como um benefício para toda a comunidade, ou, melhor dizendo, para toda a população suburbana. Deste modo, a inauguração de um negócio, a instalação de novos equipamentos, a sofisticação das instalações ou até mesmo uma liquidação era apresentada como gestos altruístas do proprietário para o seu povo.

Este argumento, contudo, não se limitava ao comércio. A construção de belas casas e edifícios e a preocupação com o estilo e a beleza da fachada das residências podem ser entendidas como uma tentativa de reverter ou minimizar a ausência de investimentos públicos em obras de infraestrutura urbana, agravada pelo contínuo processo de transferência de renda dos bairros mais pobres para os mais ricos, que, segundo Abreu (1984:27), foi indiretamente patrocinado pelo Estado.

Termos como "aristocrático palacete", "solar", "majestoso edifício", ou até os mais modestos "aprazível" e "confortável residência", eram utilizados em referência aos imóveis e, por meio deles, destacava-se a condição social do proprietário em questão.

Além da construção ou aquisição da casa própria, os empreendimentos imobiliários eram também enaltecidos como uma solução para a "crise de habitações" na cidade. A aventura no mercado imobiliário muitas vezes se iniciava como uma reserva de valor obtida no setor comercial e, progressivamente, o investidor passava a dedicar-se mais a esta tarefa. A trajetória de alguns comerciantes revela a importância do setor imobiliário como uma das principais estratégias de acumulação das camadas médias suburbanas. No periódico Subúrbios em Revista, ${ }^{12}$ o termo capitalista era o comerciante de maior prestígio e poder econômico, ligado em geral ao setor imobiliário, ao comércio atacadista, à indústria ou ao transporte viário. O termo também era aplicado aos proprietários de

\footnotetext{
${ }^{11}$ Onde um tradicional e elegante comércio havia se desenvolvido.

${ }^{12}$ Revista fundada em 1949, no bairro de Madureira. Os ideais, valores e reivindicações encontrados neste periódico são semelhantes àqueles encontrados na imprensa suburbana desde o fim do século XIX e demonstram, portanto, a permanência de um projeto de dignificação dos subúrbios empreendido pelas camadas médias suburbanas (Fernandez, 1996; 2005).
} 
negócios que, além de vultosos, tinham um caráter inovador para a época, tais como postos de gasolina ou churrascarias.

Os chamados capitalistas também se destacavam pelas atividades de benemerência, filantropia ou orientação comunitária. Percebe-se a importância da iniciativa e do potencial econômico, que era revertido em ações comunitárias, como critério de inserção neste grupo.

Sr. Serafin Gonçalves Pinto: Noutros setores de suas atividades como capitalista e filantropo, sempre que é solicitada a sua cooperação para uma iniciativa em prol do progresso de Madureira ou do bem estar e felicidade de seu povo, desempenha um papel saliente e deixa um rastro luminoso que o torna cada vez mais admirado e respeitado no seio da sociedade local (Subúrbios em Revista, maio e jun. 1949).

Neste sentido, pode-se dizer que o engajamento, sobretudo do setor comercial de Madureira, em práticas voltadas para o desenvolvimento da localidade, seria um modo de fazer com que as diferenças propriamente econômicas fossem duplicadas pelas distinções simbólicas na forma de usar estes bens (Bourdieu, 1974).

Esta distinção manifestava-se de forma marcante a partir da oposição encontrada em vários relatos e trechos da revista entre aqueles que tinham "raízes no bairro" e os "estrangeiros". Enquanto os primeiros desenvolviam vínculos de amizade, parentesco e afetividade pelo bairro, os segundos, que podiam ser imigrantes e/ou moradores de outras localidades, instalavam-se ali apenas para ganhar dinheiro. A avareza e o descompromisso com as causas do bairro eram algumas das acusações acionadas diante da recusa de alguns indivíduos em colaborar com as campanhas e movimentos organizados pelos "verdadeiros suburbanos".

Assim é que Benedict Anderson (2008: 33), ao falar de comunidades imaginadas, as descreve como limitadas, porque mesmo a maior delas possui fronteiras culturais que, embora elásticas, definem aqueles que estão dentro ou fora. Os verdadeiros madureirenses ou amigos dos subúrbios seriam aqueles que não apenas ganhavam dinheiro no bairro, mas procuravam investir onde prosperavam e moravam. Tratava-se de um movimento de diferenciação entre aqueles que aderiam e os que não aderiam ao projeto de dignificação dos subúrbios, neste último caso, os estrangeiros. Sob outra perspectiva, neste jogo de contrastes, também importava afirmar a existência de uma elite suburbana, frente aos grupos populares que conferiam uma imagem estigmatizante de pobreza e abandono ao subúrbio. 
Ainda que se referisse à vida social dos subúrbios nas primeiras décadas do século XX, Lima Barreto, em sua obra $O$ triste fim de Policarpo Quaresma, retrata com perfeição alguns desses valores que, acreditamos, permaneceram entre as camadas médias suburbanas: a oposição social entre os subúrbios e a cidade, a afirmação de uma identidade festiva e boêmia (Heilborn, 1984), a busca de distinção social através da reprodução de usos e costumes inspirados na "alta sociedade carioca".

É uma alta sociedade muito especial e que só é alta nos subúrbios. Compõe-se em geral de funcionários públicos, de pequenos comerciantes, de médicos com alguma clínica, de tenentes de diferentes milícias, nata essa que impa pelas ruas esburacadas daquelas distantes regiões, assim como nas festas e nos bailes, com mais força que a burguesia de Petrópolis e Botafogo. Isso é só lá, nos bailes, nas festas e nas ruas, onde se algum dos seus representantes vê um tipo mais ou menos, olha-o da cabeça aos pés, demoradamente, assim como quem diz: aparece lá em casa que eu te dou um prato de comida (...) Fora dos subúrbios, na Rua do Ouvidor, nos teatros, nas grandes festas centrais, essa gente mingua, apaga-se, desaparece, chegando até suas mulheres e filhas a perder a beleza com que deslumbram, quase diariamente, os lindos cavalheiros dos intermináveis bailes diários daquelas redondezas (Lima Barreto, 1984: 18).

Curiosamente, foi uma festa popular como o carnaval que se tornou um dos ingredientes mais poderosos de afirmação identidade suburbana, ou seja, comum ao povo suburbano ou a todos aqueles que moram no subúrbio, em oposição aos moradores dos demais bairros da cidade. A partir da lógica de inversão do carnaval, Madureira, pobre e abandonada no seu cotidiano, na festa de Momo brilhava e se destacava para a cidade:

Madureira enfrenta as maiores dificuldades no seu dia a dia: não tem gás, não tem luz elétrica suficiente, tem apenas meia-dúzia de aparelhos telefônicos e vive esquecida pelas autoridades, fazendo lembrar os desprezados bilhetes de loteria com final 13 que ninguém quer levar (...) mesmo assim, ninguém ousa falar mal do bairro graças aos famosos coretos alegóricos (Subúrbios em Revista, fev. 1949).

De acordo com Roberto Da Matta (1983), “enquanto, em outros países, o identificar-se coloca problemas de uma cultura cívica, remetendo a bandeiras, hinos, coroas ou lutas heroicas (...) ser brasileiro é dissolver-se na turba indiferenciada que dança o samba nas ruas". Nestes termos, a mobilização dos comerciantes para a construção dos $\operatorname{coretos}^{13}$ de carnaval, ao mesmo tempo em que conferia prestígio e distinção aos patrocinadores do evento, que muitas vezes contavam com a presença do prefeito na

\footnotetext{
${ }^{13}$ Os coretos carnavalescos, também chamados de coretos alegóricos, são construções desmontáveis de madeira que se assemelham a quiosques ou palanques feitos para animar o carnaval de rua. Eles, em geral, são decorados segundo um tema específico e feitos para durar apenas um carnaval.
} 
inauguração, também permitia a produção de uma igualdade mítica, diluindo as diferenças sociais, étnicas e de origem, tornando todos suburbanos e, ao mesmo tempo, brasileiros. Nas palavras de Anderson (2008:34), apesar das desigualdades efetivas, as comunidades imaginadas produzem uma profunda camaradagem horizontal.

Assim, no que diz respeito à relação entre os setores médios e populares no subúrbio, podemos falar em um permanente jogo de contrastes e, ao mesmo tempo, de partilhamento de valores, símbolos, pertencimentos e identidades. Por meio das festas populares, ${ }^{14}$ tais como o carnaval, produzia-se uma igualdade abstrata entre os diferentes extratos da população suburbana. Também, os indivíduos mais diversos tornavam-se iguais na vivência das carências cotidianas do subúrbio e, por isso, o acionamento de uma identidade suburbana conferia força política ${ }^{15}$ ao movimento de melhorias pelo subúrbio.

Sob outro aspecto, os setores populares partilhavam igualmente do desejo de ascensão social e aquisição de códigos e atributos que conferissem distinção social. As reportagens veiculadas no periódico (que tinha sua sede em Madureira) Subúrbios em Revista sobre casamentos, vida social nos clubes, formaturas de cursos de corte e costura, de datilografia, de contabilidade, recitais de piano, audições de acordeão indicam a importância desses rituais como momentos de atribuição de status.

Muitas dessas atividades, tais como os cursos de corte e costura, tinham um perfil predominantemente feminino. Silva (1985), neste sentido, destaca a importância da aquisição de habilidades femininas para a demonstração do status familiar e viabilização dos processos de ascensão social via casamento. A difusão de cursos de corte e costura por todo o subúrbio, variando em tamanho das instalações, número de alunas, tipo de organização (se privada ou assistencial), sofisticação e estilo de formatura, indica que a aquisição desta habilidade feminina constituía um valor compartilhado por diferentes segmentos sociais. Apenas o nome, tradição e prestígio do curso escolhido atuavam como elementos de distinção. A formatura dos cursos mais badalados era feita em grande estilo: com a realização de uma missa em ação de graças, pela manhã, solenidade de entrega de diplomas à tarde e, muitas vezes, à noite, havia o baile de encerramento em traje de gala, em um dos clubes sociais dos subúrbios. Os cursos mais modestos realizavam a festa de

\footnotetext{
${ }^{14}$ Em Subúrbios em Revista, há o registro e a valorização de outras festas populares, tais como as festas juninas e as festas religiosas. Carvalho (1987: 142), neste sentido, reforça a importância das festas religiosas, entre elas a Festa da Glória e a Festa da Penha, como importantes rituais de integração social e de encontro dos governantes com o povo fora dos domínios da política.

${ }^{15}$ Sobre a inserção dos comerciantes de Madureira na política ou suas relações com políticos locais, ver Fernandez (1996).
} 
encerramento em suas próprias sedes. Mesmo tratando-se de eventos mais simples, não eram menos elegantes ou solenes.

\section{Comércio, Coretos e Carnaval}

"Os coretos suburbanos, milhares de cruzeiros gastos sem o menor estímulo da prefeitura." O comentário encontrado em Subúrbios em Revista (fev. 1949) é um entre muitos que destacavam o protagonismo do setor comercial em patrocinar o carnaval e outros empreendimentos para o povo suburbano de forma espontânea, sem o auxílio do poder público.

Nas palavras de Guimarães (2011), os coretos carnavalescos são marcos simbólicos suburbanos, destacando-se os erguidos em Madureira. Segundo a autora: "Em 1920, a construção dos coretos já implicava aparto cenográfico e a aplicação de um tema, mantendo-se a função original de abrigar comissões julgadoras ou bandas de música, (...)” (Guimarães, 2011: 264).

A mesma autora acrescenta que, se no centro, os coretos tinham que se submeter às normas da prefeitura, nos subúrbios, a sua execução apresentava um caráter mais livre, exacerbado pela intensa competição. Ela afirma também que: "Da década de 1940 à de 1960, os subúrbios mais distantes buscaram manter a tradição da construção de coretos contando com a participação dos comércios locais (...)" (Guimarães, 2011: 267).

O concurso dos coretos promovia rivalidade entre os bairros do subúrbio, e quesitos tais como imponência, riqueza e criatividade atuavam como indicadores da capacidade econômica e organizacional dos comerciantes de cada localidade. Mas, apesar da competição, havia também grande confraternização entre as comissões promotoras, à medida que estavam voltadas para os mesmos objetivos de autopromoção e valorização dos subúrbios.

Por um lado, o financiamento dos coretos funcionava como uma forma de inserção na sociedade local, mas, por outro, não podemos esquecer que os coretos atraíam visitantes dos arredores e, portanto, contribuíam para aumentar as vendas.

O envolvimento do comércio com as manifestações carnavalescas não é uma novidade. Von Simson (1984: 190) descreve como o setor comercial de São Paulo, entre a segunda metade do século XIX e início do século XX, teve participação ativa na transformação dos folguedos carnavalescos da cidade. A autora distingue quatro fases do 
envolvimento do comércio paulistano com o carnaval. A primeira fase caracterizou-se pela venda de apetrechos carnavalescos e artigos de luxo para a festa. A segunda foi marcada pelo apoio do setor comercial às atividades carnavalescas, com iluminação das ruas e exposição dos estandartes nas vitrines das lojas. Na terceira fase, o comércio patrocinava alguns carros alegóricos com a propaganda de seus produtos e, finalmente, contribuía com as atividades carnavalescas nos bairros, enfeitando ruas, coretos e desfiles de préstitos.

Embora possamos reconhecer no patrocínio dos coretos carnavalescos de Madureira pelo comércio local práticas e intenções semelhantes àquelas descritas por Von Simson (1984), é o apelo aos sentimentos de dedicação e divulgação da localidade a principal estratégia de mobilização dos comerciantes para a festa. Queremos assim enfatizar que as razões práticas, voltadas para o lucro e retorno financeiro do evento, não estavam desvinculadas dos aspectos extraeconômicos, relacionados à distinção e pertencimento a grupos de status locais atribuídos a partir da contribuição generosa dos comerciantes de Madureira para a realização desta grande festa do povo.

A partir da leitura da imprensa suburbana do início do século, pode-se observar que alguns atores ligados a esta imprensa e, portanto, ao movimento de dignificação dos subúrbios, também participavam ativamente das sociedades carnavalescas que desfilavam em dias de folia em elaborados carros alegóricos, sendo um prenúncio das relações futuras entre o carnaval e este movimento. E, neste sentido, confirma também a natureza comunitária das associações carnavalescas: a importância das relações de parentesco e/ou vizinhança e amizade (Da Matta, 1983; Zaluar 1985; Goldwasser, 1975).

Além da adesão a este projeto de base comunitária, podemos elencar também o gosto puro e simples pela festa carnavalesca em seus aspectos lúdicos e simbólicos.

O carnaval carioca é festa neste sentido amplo: é uma brincadeira com o tempo que interrompe seu fluxo por uns poucos dias (e nele todo mundo brinca, se fantasia, pula na rua ou nos bailes, compete e se exibe num desfile, simplesmente descansa ou trabalha para o carnaval) e retorna renovado (Cavalcanti, 1993: 40).

Considerando o número significativo de portugueses na formação do comércio de Madureira desde sua origem, é possível sugerir que estes tenham trazido de seu país de origem certa familiaridade com a cultura carnavalesca, ${ }^{16}$ facilitando a adesão ao projeto

${ }^{16}$ O entrudo é uma manifestação carnavalesca de origem portuguesa que chegou ao Brasil no século XVII.
O Zé-Pereira surgiu em meados do século XIX, no Rio de Janeiro. Segundo Moraes (1987), era 
dos coretos carnavalescos, seja através do patrocínio ou da participação nas comissões organizadoras. O próprio criador dos coretos, José Costa, tinha origem portuguesa. Da mesma forma, Armindo Fonseca, próspero comerciante de Madureira, filho do português José Costa da Fonseca (estabelecido no Brasil desde 1912), ao ser indagado se seu pai participava das primeiras comissões organizadoras do evento, responde: sim, ele e os velhos portugueses.

Os imigrantes portugueses recém-chegados ao Brasil e estabelecidos no comércio suburbano parecem ter buscado formas de pertencimento, participação e integração social com os recursos culturais de que dispunham. O carnaval pode ter sido a escolha ideal, já que, além de ser comum à cultura dos dois países (no Rio de Janeiro em especial), constituía-se em uma festa de grande alcance social, capaz de mobilizar os mais diversos estratos da população com folguedos que transformavam a cidade nos quatro dias de folia.

Como num quadro de imagens rabelaisianas, no qual o carnaval ou carnavalesco adquire um sentido de renascimento e renovação (Bakhtin, 1987), a história dos coretos de Madureira curiosamente se relaciona à fundação de uma casa funerária. Seu proprietário, o português José Costa, estabelecido no bairro desde 1917 e tendo que negociar com a morte e a tristeza da população local, resolveu proporcionar alegria e divertimento para seus fregueses (Subúrbios em Revista, fev. 1949). Assim, em 1920, o comerciante construiu sua obra-prima - Cruzador em Alto-Mar - o primeiro de uma série numerosa de coretos projetados ao longo de vários carnavais. Pouco a pouco, os coretos alegóricos espalharam-se pelos bairros dessa região, passando a ser identificados como uma tradição tipicamente suburbana. No final da década de 1940, os coretos já haviam se consagrado como importantes símbolos da localidade, e, sobretudo, como exemplos da autonomia e espírito de iniciativa dos empreendedores suburbanos.

Enquanto no centro da cidade, a ornamentação corre por conta da prefeitura nos bairros ela é feita graças aos esforços dos moradores e do comércio local. (...) São os tradicionais coretos. O mais famoso deles todos é o de Madureira (Subúrbios em Revista, mar. 1949:18).

Com apenas algumas interrupções, José Costa construiu seus coretos até 1936, encerrando então suas atividades de cenógrafo. Para que Madureira continuasse a manter

originalmente formado por grupos de portugueses que saíam às ruas no carnaval tocando zabumbas e tambores. 
sua tradição carnavalesca, relata Subúrbios em Revista (mar. 1949), o comércio de Madureira passou a contratar os serviços de outros artistas.

A partir do sucesso de seu primeiro coreto, o artista construiu as seguintes obras de arte:

\begin{tabular}{|c|c|}
\hline Ano & Coreto Carnavalesco \\
\hline 1921 & Castelo de São Julião \\
\hline 1923 & Avião Caproni \\
\hline 1924 & Palácio Oriental \\
\hline 1925 & Torre Eiffel $^{17}$ \\
\hline 1926 & Solar Indiano \\
\hline 1927 & Castelo Colonial \\
\hline 1928 & Solar no Japão \\
\hline 1929 & Castelo de Bagdá \\
\hline 1933 & O Brasil Resplandece \\
\hline 1936 & Paz nas Américas \\
\hline
\end{tabular}

Fonte: Subúrbios em Revista, fev. 1949.

O coreto de 1924, Torre Eiffel, foi imortalizado pela pintura de Tarsila do Amaral, do mesmo ano, e denominada Carnaval em Madureira. Durante muito tempo, acreditavase que o motivo da figura seria uma licença poética da artista, que, recém-chegada da França, teria retratado a Torre Eiffel em pleno subúrbio. Esta versão foi desmentida em 2014 pelo IGHBI - Instituto Geográfico e Histórico da Baixada do Irajá, ao esclarecer que o coreto de fato existiu. De acordo com o professor Roberto Mattos de Mendonça: "O coreto media 18 metros de altura com uma base quadrada de 24 metros, contando com três pavimentos giratórios, um farol, um balão e 400 lâmpadas elétricas" (Torre, 2014).

Em 1936, um dia após a inauguração do coreto, um temporal destruiu todo o trabalho de José Costa. De acordo com relato de Subúrbios em Revista, outros artistas foram chamados para manter a tradição. O Senhor José Costa continuou a colaborar com a comissão promotora, sem, contudo, intervir diretamente na fabricação do coreto. Em

\footnotetext{
${ }^{17}$ Há uma imprecisão na descrição da revista sobre a história dos coretos alegóricos de Madureira. Esta aponta a construção da obra Torre Eiffel em 1925 e não em 1924, data da pintura de Tarsila do Amaral que retrata o mesmo coreto.
} 
1946, sob a liderança do comerciante Armindo Fonseca e Ayres Augusto Pereira, foi construído o coreto A vitória das Nações Unidas.

Tanto a versão da revista quanto a fala de alguns entrevistados tendem a enfatizar excessivamente o lado artístico e empreendedor do proprietário da casa funerária, dando a impressão, por vezes, de tratar-se de uma iniciativa solitária do comerciante. A ênfase no talento, criatividade e sua habilidade em trabalhar a madeira sugere a importância da arte e da criação na festa carnavalesca, ao valorizar a capacidade única e exclusiva do cenógrafo em produzir o "espetáculo visual" dos coretos. Assemelha-se, num certo sentido, ao papel atribuído ao carnavalesco nas escolas de samba atuais (Cavalcanti, 1993), na medida em que é ele que concebe e visualiza o sonho da escola na avenida. Entretanto, a valorização excessiva do talento desses artistas tende a mascarar o caráter coletivo do processo de produção da festa carnavalesca.

Segundo o comerciante Armindo Fonseca, o proprietário da casa funerária nunca fez sozinho os coretos de Madureira. Embora a ideia inicial e a concepção dos coretos tenha sido de José Costa, sua construção sempre foi um empreendimento coletivo do comércio de Madureira que, através da organização de comissões promotoras, se cotizava para erguer as obras.

Fazendo uso desta antiga tradição do bairro, Subúrbios em Revista lançou em 1949 a campanha para a reedição dos coretos alegóricos de Madureira, enfatizando a contribuição destas construções no passado para a divulgação e popularidade alcançada pelo bairro.

De fato, Subúrbios em Revista exerceu um efeito catalisador sobre esta antiga tradição. Desde 1946, esta prática estava abandonada, devido à dificuldade encontrada pelas comissões organizadoras em arrecadar recursos entre os comerciantes e, em muitos casos, terminar a obra a tempo dos festejos de carnaval.

Os comerciantes já se cotizavam antes da existência da revista, já havia esse esquema montado, e procuravam umas pessoas, mas nunca, sabe, havia, vamos dizer assim, uma organização. Acabava no sábado de carnaval, estava pronto para inaugurar. Às vezes inaugurava no domingo, até na segunda-feira, então isso foi incomodando as pessoas escolhidas para fazer comissão (Carlos G. Potengy Júnior. Entrevista).

Em 1949, então, Armindo Fonseca se encarregou de formar uma comissão promotora, junto com mais oito comerciantes do bairro, e o diretor da revista, Carlos Gomes Potengy, responsabilizou-se pela parte artística, contratando seu pai, José Gomes 
da Silva Potengy, antigo cenógrafo de carros alegóricos de ranchos, ${ }^{18}$ para a execução do coreto.

O sucesso deste empreendimento e a grande mobilização do setor comercial fizeram com que Potengy assumisse a criação e execução da obra nos anos seguintes, tornandose o grande maestro deste evento. Assim como no passado José Costa tornou-se famoso por suas obras de arte, o domínio de Potengy sobre o "saber carnavalesco" fez com que os coretos, a partir dessa data, estivessem intimamente relacionados à sua imagem e à da revista, dando por vezes a impressão de tratar-se de mais um dos eventos criados por Subúrbios em Revista.

O tradicional carnaval de Madureira, cuja semente foi lançada por Subúrbios em Revista, mas que só germinou graças ao estímulo de verdadeiros madureirenses que, pela sua dedicação ao subúrbio onde estão estabelecidos, conseguiram superar a barreira anteposta por meia dúzia de hipócritas que o expressivo acontecimento serviu para revelar (Subúrbios em Revista, fev.1949: 3).

A partir da liderança da revista sobre este empreendimento, foram introduzidas algumas modificações na organização do evento carnavalesco, tornando-o mais lucrativo para o comércio que o havia patrocinado. Ele passou a ser inaugurado uma semana antes do carnaval, prolongando a festa e atraindo um número maior de pessoas ao bairro. As duas grandes escolas de samba de Madureira, Portela e Império Serrano, além de outras menores como Império da Colina, Prazer da Serrinha, Unidos para Sempre, Unidos da Congonha, Paz e Amor, Unidos de Turiassu e Unidos de Irajá, passaram a desfilar em torno do coreto na segunda e terça-feira de carnaval. Como prêmio de participação e, em alguns anos, por julgamento de quesitos, eram ofertadas taças pelo comércio local.

O desfile contribuiu para aumentar a repercussão e o brilhantismo do carnaval de Madureira, não apenas pelo fato de que estas agremiações vinham obtendo crescente projeção nacional, mas particularmente pelo fato de que as já mencionadas duas grandes escolas de samba do bairro - Portela e Império Serrano - vinham acumulando sucessivas vitórias nos desfiles oficiais da Praça Onze. ${ }^{19}$

\footnotetext{
18 "Os ranchos carnavalescos surgiram por volta de 1872 e diferenciavam-se das grandes sociedades pela origem marcadamente popular. Sua criação sofreu influência nordestina, que se caracterizou por incorporar ao carnaval elementos de procissões religiosas de tradição negra e de manifestações folclóricas típicas do Dia de Reis" (Dicionário Cravo Albin de Música Popular Brasileira, 2001).

19 “Em 1948, Portela ficou em $3^{\circ}$ e o Império em $1^{\circ}$. De 1949 a 1951, o Império ficou em $1^{\circ}$ lugar. Em 1953, a Portela foi campeã, seguida do Império. Em 1954, a Portela tirou o $2^{\circ}$ lugar. Em 1955, a Portela chegou em $2^{\circ}$ e o Império em $1^{\circ} \mathrm{e}$, finalmente, em 1957, inverteram-se as posições" (Augrass, 1992:10).
} 
O papel promocional e também coercitivo de Subúrbios em Revista fez com que este evento contasse com a participação da grande maioria do comércio local. A revista não só cedia amplo espaço para a divulgação dos preparativos e cobertura da festa, como também publicava em suas páginas os nomes dos comerciantes, com seus respectivos estabelecimentos, que haviam colaborado ou não para a mesma.

\begin{abstract}
Atitude lamentável: a respeito do dono de uma perfumaria em Madureira que prometeu colaborar com 500 cruzeiros e passado o carnaval só quis pagar 200. (...) A sua miserável contribuição não foi aceita e ele embora fosse chamado de 'sujo' por um dos membros da comissão, ficou todo satisfeito porque conseguiu acumular no 'pé de meia', mais 'duzentões'. O fato fica como uma advertência aos que negociam a crédito. Cuidado com o dono da perfumaria na estrada Marechal Rangel (...) O homem vende sabonete mas é sujo pra cachorro ... (Subúrbios em Revista, mar. 1949: $15)$.
\end{abstract}

A progressiva incorporação do carnaval, em especial o samba das camadas populares, como um símbolo da cultura nacional no período do pós-guerra fez com que o carnaval dos coretos adquirisse também forte caráter nacionalista. Isto é, a colaboração ou não para o evento distinguia os estrangeiros dos verdadeiros madureirenses. $\mathrm{O}$ termo estrangeiro podia ser utilizado em referência aos comerciantes que apenas trabalhavam, mas não moravam no bairro, ou àqueles que realmente possuíam outra nacionalidade. ${ }^{20}$ A adesão dos imigrantes às várias iniciativas comunitárias, mas sobretudo ao carnaval, festa popular e expressão da identidade nacional, passou a ser vista como uma demonstração de gratidão ao Brasil. Nestes termos, a recusa em contribuir para a festa era o bastante para acionar comentários irônicos e, em alguns casos, agressivos da revista sobre os comerciantes estrangeiros, aproveitadores do esforço alheio e do povo de Madureira. A identidade estrangeira do comerciante era destacada pelas referências jocosas ao seu sotaque, à sua aversão cultural, social e étnica à festa e à sua avareza.

Houve quem afirmasse que não contribuía porque 'carnaval era festa de negros' (...) mas depois de recontar a féria levada pelos 'negros', deve estar lamentando que Madureira não tenha quatro carnavais por ano (Subúrbios em Revista, mar. 1949).

\footnotetext{
${ }^{20}$ No período estudado, a referência aos estrangeiros de fato era atribuída a pessoas de outra nacionalidade. A partir de meados da década de 1960, com o processo de expansão imobiliária em direção à zona sul, é que este termo começou a ser utilizado de forma mais ambígua. A "democratização da zona sul" e a integração viária da cidade (Abreu, 1988) abriram novas opções de moradia aos comerciantes dos subúrbios.
} 
Dois 'sapateiros' se negaram a colaborar porque para eles, carnaval não interessava (...), porém no momento oportuno, trataram de ficar na porta batendo palmas. 'Entra freguês, eu tem sapata bela' ... O meu botina é de elite (Subúrbios em Revista, mar. 1949).

Três 'estrangeiros' apenas. Foram eles os italianos fascistas, donos da loja de sapateiro cognominada 'A Alvorada' fazendo referências desairosas para o carnaval de Madureira, esses 'carcamanos' declararam à comissão que não assinaram porque não iriam perder tempo em assistir os festejos nesta localidade (Subúrbios em Revista, fev.1951).

Os negociantes em questão, além de sofrerem represálias por parte da comunidade durante o ano, nas noites de folia, as gambiarras em frente aos seus estabelecimentos permaneciam apagadas. Contudo, é importante enfatizar que a atitude de boicote e ironia veiculada na revista não era expressão exclusiva das convicções de seu redator, mas estimuladas pelos comerciantes das comissões promotoras do carnaval. Neste sentido, Subúrbios em Revista, ao exercer sua capacidade de formação de uma opinião pública (Bourdieu,1981; Champagne,1996), potencializou a força coercitiva deste movimento, permitindo enfatizar a união, o consenso entre os "verdadeiros madureirenses", aumentando a eficácia política deste movimento. Subúrbios em Revista tornou-se assim um importante veículo de divulgação dos anseios dos estratos médios suburbanos, entre os anos 1940 e 1960, ao mesmo tempo que se legitimou como porta-voz do movimento de dignificação dos subúrbios (Fernandez, 1996) e foi capaz de imprimir novos ritmos e significados a ele.

Graças à mobilização e à capacidade de divulgação da revista, os coretos alegóricos de Madureira tornaram-se a mais importante estratégia de promoção do bairro, dos subúrbios. Através da linguagem própria do carnaval, a criação de uma igualdade abstrata entre os moradores do subúrbio tornava-se possível a partir da integração dos diferentes segmentos sociais na festa carnavalesca. Ainda que os vários grupos sociais tivessem orientação ou participação distinta na folia, simbolicamente, recriava-se um subúrbio unido pela alegria e riqueza de fantasias e alegorias.

\section{Considerações Finais}

O objetivo deste artigo foi perceber como cidades e bairros também formam comunidades imaginadas, que são afetadas pelo contexto da época e pelas migrações. Ao analisar a inserção de imigrantes portugueses no bairro de Madureira e sua participação nessa "comunidade imaginada", especialmente através do comércio e do carnaval, 
pudemos perceber a importância adquirida pelo patrocínio dos coretos alegóricos como importante critério de distinção entre aqueles que "tinham raízes no bairro" e os “estrangeiros", que se estabeleciam em Madureira apenas para obter lucros. Junto aos critérios localistas de afetividade e pertencimento ao bairro, a mobilização do comércio local (composto por muitos imigrantes, em sua maioria de origem portuguesa) para a realização do carnaval adquiriu um sentido mais profundo de adesão a esta importante manifestação da cultura brasileira, tornando-se gesto de gratidão ao país e à população brasileira.

A incorporação do desfile das escolas de samba em torno dos coretos contribuiu para aumentar a fama e o brilhantismo do carnaval de Madureira, já que as escolas de samba, a partir do período estudado, adquiriram uma crescente projeção no contexto nacional. Deste modo, a participação das camadas populares no evento reforçou o prestígio e proporcionou um caráter socialmente abrangente do movimento de dignificação dos subúrbios.

\section{Referências}

ABREU, Maurício. Da habitação ao habitat: uma interpretação geográfica da evolução da questão da habitação popular no Rio de Janeiro (1850-1930). Seminário: Habitação popular no Rio de Janeiro: Primeira República. Rio de Janeiro: Fundação Casa de Rui Barbosa / Iuperj/ Ibam, 1984. . Evolução urbana do Rio de Janeiro. Rio de Janeiro: Zahar/Ibam, 1988.

ALBIN, Ricardo Cravo Albin. Dicionário Cravo Albin da música popular brasileira. Rio de Janeiro: DNL, 2001. Versão on line. Disponível em: < http://dicionariompb.com.br/>. Acesso em 10 set. 2014.

ANDERSON, Benedict. Comunidades imaginadas. São Paulo: Companhia das Letras, 2008.

AUGRASS, Monique. Medalhas e brasões: a história do Brasil no samba. Rio de Janeiro. Centro de Documentação Contemporânea do Brasil, 1992.

BAKHTIN, Mikhail. A cultura popular na Idade Média e no Renascimento. São Paulo: Hucitec, 1987.

BARRETO, Lima. Triste Fim de Policarpo Quaresma. São Paulo, Ática, 1984.

BASSANEZI, Maria S.C. Beozzo. "Imigrações Internacionais no Brasil: um panorama histórico." In: PATARRA, Neide (Coord.). Emigração e Imigração Internacionais No Brasil contemporâneo. v.1, São Paulo: FNUAP, 1995.

BRASIL. IBGE. Recenseamento Geral do Brasil, 1920, 1940, 1950, 1960, 1970, 1980, 1991, 2000. 
BOURDIEU, Pierre. A opinião pública não existe. In: THIOLLENT, Michel. Crítica Metodológica, investigação social e enquete operária. São Paulo: Polis, 1981. p. 137-151. Condição de classe e posição de classe. In: AGUIAR, Neuma (Org.). Hierarquias em classes, Zahar, Rio de Janeiro, 1974.

CAVALCANTI, Maria Laura V. de C. Onde a Cidade se encontra: o desfile das escolas de samba no Rio de Janeiro. Tese (doutorado em Antropologia Social). Rio de Janeiro: PPGAS/ UFRJ, 1993.

CARVALHO, José Murilo de. Os bestializados: o Rio de Janeiro e a república que não foi. São Paulo: Companhia das Letras, 1987.

CHALHOUB, Sydney. Trabalho, lar e botequim: o cotidiano dos trabalhadores no Rio de Janeiro da Belle Époque. São Paulo: Brasiliense, 1986.

CHAMPAGNE, P., Formar a opinião: o novo jogo político. Petrópolis: Vozes, 1996.

COSTA LEITE, Joaquim da. "O Brasil e a emigração portuguesa (1855-1914)”. In: FAUSTO, Boris (Org.). Fazer a América. São Paulo: EDUSP, 2000. p. 177-200.

DA MATTA, Roberto. Carnavais, malandros e heróis: para uma sociologia do dilema brasileiro. Rio de Janeiro: Zahar, 1983.

FERNANDEZ, Annelise Caetano Fraga. Assim é o meu subúrbio: o Projeto de dignificação dos subúrbios entre as camadas médias suburbanas de 1948 a 1957. Dissertação (mestrado em Sociologia e Antropologia). Universidade Federal do Rio de Janeiro, Rio de Janeiro, 1996.

Orgulho suburbano: o projeto de dignificação dos subúrbios do Rio de Janeiro na imprensa de bairro, 1948-1957. Cadernos CERU, série 2, n.16, p.143-162, 2005.

GUIMARÃES, Helenise. Batalhas de confete e coretos carnavalescos: o desenho de uma paisagem efêmera no carnaval carioca nas décadas de 1930 a 1950. Textos escolhidos de cultura e arte populares. Rio de Janeiro, v.8, n. 2, p. 259-272, nov.2011.

GOLDWASSER, Maria Julia. O palácio do samba. Rio de Janeiro: Zahar, 1975.

HEILBORN, Maria Luiza. Conversa de portão: juventude e sociabilidade em um subúrbio carioca. Dissertação (mestrado em Antropologia), Programa de Pós-Graduação em Antropologia Social do Museu Nacional / UFRJ, Rio de Janeiro, 1984.

LEVY, M.S.F. “O papel da migração internacional na evolução da população brasileira (18721972)." Revista de Saúde Pública, São Paulo, v.8, complemento, 1994.

MARTINS, Ronaldo Luiz. Mercadão de Madureira: Caminhos de Comércio. Rio de Janeiro: Condomínio do Entreposto Mercado do Rio de Janeiro, 2009.

MENEZES, Lená Medeiros. "Jovens portugueses: histórias de trabalho, histórias de sucessos, histórias de fracassos". In: GOMES, Ângela de Castro. Histórias de imigrantes e de imigração no Rio de Janeiro. Rio de Janeiro: 7 letras, 2000. 
MURTA, Ivana Benevides Dutra et al. Mercadão de Madureira: é uma casa portuguesa com certeza. $32^{\circ}$ Encontro da ANPPAD. Rio de Janeiro, 6 a 10 set. 2008. Disponível em: <http://www.anpad.org.br/admin/pdf/EOR-A2732.pdf >. Acesso em: 02 set. 2014.

NEVES, Lúcia Ma B.P.; FERREIRA, Tânia M $M^{a}$ T.B. "Portugal, França e Brasil: representações imaginadas (1808-1914)”. In: MENEZES, Lená Medeiros; ROLLEMBERG, Denise; MUNTEAL FILHO, Oswaldo. Olhares sobre o político. Rio de Janeiro: Eduerj, 2002.

ROWLAND, R. "La migración a grandes distancias y sus contextos: Portugal y Brasil. Revista Estudios Migratorios Latinoamericanos, año 7, nº 21, 1992.

SALEM, Tânia. Famílias em camadas médias: uma revisão da literatura recente. Boletim do Museu Nacional. Rio de Janeiro: Museu Nacional, n. 54, 30 out. 1985.

SILVA, Eduardo. As queixas do povo. Rio de Janeiro: Paz e Terra, 1988.

SILVA, Maria Alice de Oliveira. Rendas, babados, bilros e crochês: a construção social da mulher de prendas domésticas. Dissertação (mestrado em Antropologia). Universidade Estadual de Campinas, Campinas, 1985.

TORRE Eiffel de Madureira: Instituto do Irajá desvenda o mistério. Veja Rio, 12 mar. 2014. Disponível em: <http://vejario.abril.com.br/blog/rj450/uncategorized/torre-eiffel-de-madureirainstituto-do-iraja-desvenda-misterio>. Acesso em: 25 jul. 2014.

VELHO, Gilberto. A utopia urbana: um estudo de antropologia social. Rio de Janeiro: Editora Zahar, 1989.

. Individualismo e cultura. Rio de Janeiro: Editora Zahar, 1994.

VON SIMSON, Olga Rodrigues de Moraes. A burguesia se diverte no reinado de momo. São Paulo, 283 p. Dissertação (Mestrado). Faculdade de Filosofia, Letras e Ciências Humanas da Universidade de São Paulo, 1984.

ZALUAR, Alba. A máquina e a revolta. São Paulo: Brasiliense, 1985.

Recebido em: 20/09/2014

Aprovado em: 15/11/2014 